\title{
Covid-19: UK starts social distancing after new model points to 260000 potential deaths
}

\author{
Elisabeth Mahase
}

The BMJ

The UK government has been forced to change its plan of attack for covid-19 after modelling showed that, although the plan might reduce peak healthcare demand by two thirds and cut deaths by half, it would still result in 260000 deaths and overwhelm the health system-most notably in intensive care units (ICUs).

The government has announced that everyone should now begin social distancing, meaning avoiding contact with others as much as possible. Whole households should also quarantine themselves for 14 days if someone has a symptom of covid-19, and those who are at high risk for severe disease-including pregnant women, people over 70, and those with certain health conditions-should isolate themselves for 12 weeks, starting from this weekend.

The prime minister, Boris Johnson, said, "Now is the time for everyone to stop non-essential contact with others and all unnecessary travel. We need everyone to start working from home where they can. You should avoid pubs and restaurants."

He added that he would not ban mass gatherings, but he advised people against them and said that public services such as police and ambulances would not be available for large events.

\section{Change in attitude}

These measures represent a major change in attitude by the government, which had previously only told people with symptoms to isolate at home for seven days and suggested that people over 70 may have to self-isolate.

This change comes after a modelling study, ${ }^{1}$ carried out by the MRC Centre for Global Infectious Disease Analysis at Imperial College London, assessed the government's previous plan in light of two new pieces of information: a refined assessment of what the NHS could cope with; and updates from clinicians in the UK and Italy, showing that ICU requirements were nearly twice what was anticipated.

Neil Ferguson, study lead and coauthor, said, "The combination of those things means that we can conclude that, even with the interventions announced last week, there would be a risk of ICUs being overwhelmed. And that is why we need to act now with more intensive interventions to prevent that from happening."

The research compared what would happen if the government followed its plan, slowing but not stopping transmission, with a second scenario where it would implement intensive interventions to interrupt transmission and reduce case numbers to low levels.

The researchers found that the first plan-combining home isolation of cases and social distancing of people over 70_-would lead to a peak over a three to four month period during the spring and summer and would reduce healthcare demand and deaths, but it would still result in 260000 deaths and a health system unable to cope.

\section{Entire population}

The second plan the researchers considered, which the government has now announced, involved a combination of social distancing of the entire population, home isolation of cases and household quarantine of their family members, and possible school and university closures.

Ferguson said that, by following this second plan, people could "reverse transmission" but that this would "only last for a few months in the first instance, at which point we might be able to take a breather if we have driven down cases."

He added, "But we are not out of the woods at that point, and the likelihood is that, if we go back to normal and don't have other interventions, then transmission will redeem again and we will have to repeat the same cycle. The only exit strategy [in the] long term for this is really vaccination or other forms of innovative technology that allows us to control transmission." He still predicted a "significant health impact . . . but we will be talking about maybe tens of thousands of deaths, maybe single digits of thousands, maybe depending on how early we are-maybe a few thousand."

England's chief medical officer, Chris Whitty, said that his announcement last week that only people admitted to hospital would be tested for the virus had caused upset, especially among healthcare staff who were concerned that they would have to quarantine unnecessarily with a mild symptom, as they could not be tested.

In the latest update Whitty said, "We do plan to scale up testing every single week, moving out into the wider community. The thing which would be transformational would be a test to see if you have previously had the disease. This is being developed by Public Health England.”

He added that "healthcare and indeed other critical workers will be tested in the next stage of increasing the capacity." 
After calls for increased transparency, Johnson has also promised daily briefings.

1 Ferguson NM, Laydon D, Nedjati-Gilani G, et al. Report 9: Impact of non-pharmaceutical interventions (NPIs) to reduce COVID-19 mortality and healthcare demand. Imperial
College London. 16 Mar 2020. https://www.imperial.ac.uk/mrc-global-infectious-diseaseanalysis/news--wuhan-coronavirus/.

Published by the BMJ Publishing Group Limited. For permission to use (where not already granted under a licence) please go to http://group.bmj.com/group/rights-licensing/ permissions 